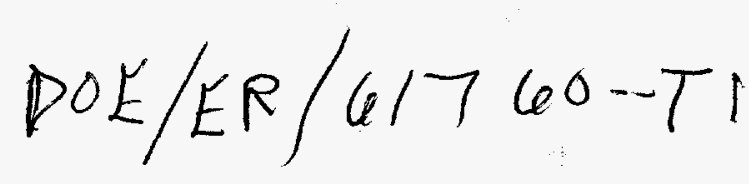

\author{
PROGRESS REPORT \\ for August 15, 1994 - August 30, 1995 \\ Grant \# DE-AI03-94ER61760
}

\begin{abstract}
Additional Development of Remote Sensing Techniques for Observing
Morphology, Microphysics, and Radiative Properties of Clouds

and Tests Using a New, Robust $\mathrm{CO}_{2}$ Lidar
\end{abstract}

Wynn L. Eberhard, Janet M. Intrieri, and W. Alan Brewer

NOAA Environmental Technology Laboratory

Boulder, Colorado

\title{
PROJECT ABSTRACT
}

The bulk morphology and microphysical characteristics of a cloud are both important in determining the cloud's effect on radiative transfer. A better understanding of all these properties, and the links among them, are needed for developing adequate parameterizations of these components in climate models. The objective of this project is to develop remote sensing techniques for observing key cloud properties, including the linkages. The research has technique development and instrument development prongs.

(1) Develop and validate new techniques involving $\mathrm{CO}_{2}$ lidar for observing microphysical properties. This lidar provides some unique information because of its different wavelength and refractive index of ice and water particles. These techniques are:

a) $\mathrm{CO}_{2}$ lidar extinction-backscatter method to obtain path-averaged drop size distribution. An important application would be study of the effect of aerosols on drop sizes and hence radiative transfer (Twomey effect).

b) Dual-wavelength $\mathrm{CO}_{2}$ lidar method to obtain profile of drop sizes and perhaps number density.

c) Dual-wavelength $\mathrm{CO}_{2}$ lidar method to discriminate between ice and water clouds.

Classification of cloud type is important because typical characteristics are quite different.

d) Radar/lidar backscatter method for cirrus particles sizes, number density, and ice content. We must better account for the effect of nonspherical particles.

e) Potential of Doppler lidar measurements of cirrus particle vertical motions for determining microphysical characteristics.

f) LIRAD (lidar-radiometer) method adapted to $\mathrm{CO}_{2}$ lidar for obtaining cirrus emissivity and optical depth. This will permit study of this fundamental optical parameter and its links with other cloud parameters.

g) Can LIRAD results with a shortwave lidar (e.g., Spinhirne's lidar and AERI at CART) replace the $\mathrm{CO}_{2}$ lidar in the lidar/radar method (item c)?

(2) Design and demonstrate a new version of $\mathrm{CO}_{2}$ lidar with potential for eventually engineering into a CART instrument. The design characteristics of the breadboard system in this project 
include:

a) RF-excited lasers for long gas lifetime.

b) Wavelength switching capability for ice/water discrimination and for water vapor DIAL.

c) Improved Doppler accuracy.

d) Elimination of continual operator intervention and frequent maintenance.

\section{SUMMARY OF PROGRESS TO DATE}

\section{Measurements at CART}

A major accomplishment was participation in the Remote Cloud Sensing (RCS) IOP at the SGP CART during April 1994 with two instruments. Our emphasis was technique development. We operated our older $\mathrm{CO}_{2}$ lidar and obtained data on cirrus, middle cloud, and low stratus regimes. We also operated the narrowbeam infrared radiometer during both cloudy and clear skies. (This instrument was on loan from M. Platt, who built it under the IDP program.) Our measurements were coordinated with those of cloud radars and other lidars participating in the IOP. Coordination was also achieved with flights of an instrumented aircraft, which provided in situ data for comparison with microphysical parameters obtained from our new remote sensing techniques.

The preliminaries of analyzing this data set have been completed. The lidar had a new data acquisition system, and we procured a new computer system for post-processing, so software modifications were required. One troublesome problem with the new data system (solved after the experiment) was a poor connection of the clock chip in the signal digitizer, which caused strong, random noise spikes in the backscatter data. Software was written to remove these spikes, enabling analysis of RCS data to proceed. Lidar calibration data were processed. Software was written to process the infrared radiometer data. Additional accomplishments are in the individual techniques discussed below. Processed lidar data and calibrated radar data are now available, so technique evaluation can now commence in earnest.

\section{Robust lidar development}

Good progress in this task is now being made after overcoming some early setbacks. We had an aggressive schedule in the hope of finishing a single-wavelength version of the new lidar in time for the RCS, but we encountered two major problems. One was the discovery of some mechanical flaws in the original design of the system's laser amplifiers, which are built in-house. The second was the departure of our post-doc, who was building the lidar hardware, for a permanent position. Another post-doc with good qualifications started on this project in July 1994. He changed the amplifier design, and work is now going forward at a good pace.

Some important milestones in building the breadboard lidar are as follows:

* The system's laser oscillators were first built in-house, but a superior commercial product is now available. We will use the latter, although modifications to the optics are required. 
* The transportable container and scanning telescope for the lidar are finished.

* The redesigned laser amplifiers have small-signal gain sufficient to meet the planned performance specifications.

* Beam quality and frequency stability have been good in bench tests conducted so far (continuous lasing). The next step is similar tests in the pulsed mode.

* Receiver electronics have been designed and built, with complex demodulator and amplifier performance superior to those in our old lidar.

Our plan is to complete and test the lidar at a single wavelength first. Then the wavelength switching and use of the $\mathrm{C}^{13}$ isotope (optimum for cloud sensing) will be incorporated and tested. These initial tests will be here in Boulder. NASA plans to fly an instrumented aircraft studying cirrus during the 1996 spring IOP, and the CART cloud radar should be operating by that time. This will also be an excellent opportunity for technique testing and validation, so we plan a field demonstration of the completed lidar during the 1996 spring IOP.

\section{Technique Development}

*** Average drop size

The RCS provided a good data set of lidar and in situ aircraft data for testing this method. Software to retrieve the drop sizes from the lidar data was written. An example is shown in Fig. 1. We are now processing all cases and will compare with aircraft results.

*** Drop size and number profiles

This idea was examined theoretically for simple, typical cases. The conclusion was that the information was too ambiguous for any useful result.

*** Ice/water discrimination

The theory (completed earlier) was published in Journal of Atmospheric and Oceanic Technology. Further work on this awaits completion of the two-wavelength capability in the new lidar.

*** Cirrus microphysics from radar/lidar

Some good data are available from the RCS to demonstrate this technique. Unfortunately, we were unable to obtain coincident lidar, radar, and overhead aircraft data without lower clouds in the way. However, the available data will be analyzed to see if results are reasonable and for possible use by others. This is worthwhile, because a different radar was used than during our original tests of the technique.

*** Information from Doppler lidar

Our initial theoretical analysis of differential velocities measured by Doppler lidar and radar confirmed that some information is available. One product is the breadth of the cirrus size distribution, but some ambiguity exists. Separation of air and particle vertical motions with 
differential Doppler lidar and radar also appears difficult, but may be possible in some instances. Theoretical work continues on these possibilities.

We will also investigate the use of Doppler and backscatter from the lidar alone in a manner already demonstrated for radar to determine if useful results for cirrus particle sizes or ice content can be obtained. This approach would be most useful when the radar is not sensitive enough to detect the cloud.

\section{*** Optical properties from LIRAD}

We wrote software to implement the LIRAD technique with our $\mathrm{CO}_{2}$ lidar data. Fig. 2 is an example of how $\mathrm{CO}_{2}$ lidar, cloud radar, and infrared radiometer data can be used to obtain bulk, microphysical, and optical properties of cirrus simultaneously.

Infrared radiometer data from the RCS have been processed (Fig. 3). They are being examined for consistency and accuracy, including comparison with AERI results. Some functional problems were reported to the builder, who has already implemented changes.

\section{*** LIRAD instead of $\mathrm{CO}_{2}$ for radar/lidar microphysics?}

The first step, now in progress, is to obtain LIRAD and lidar/radar results from our RCS data. Then AERI and CART lidar data, which have much longer sampling times, will be evaluated and processed to see if like results can be obtained.

\section{DISCLAIMER}

This report was prepared as an account of work sponsored by an agency of the United States Government. Neither the United States Government nor any agency thereof, nor any of their employees, makes any warranty, express or implied, or assumes any legal liability or responsibility for the accuracy, completeness, or usefulness of any information, apparatus, product, or process disclosed, or represents that its use would not infringe privately owned rights. Reference herein to any specific commercial product, process, or service by trade name, trademark, manufacturer, or otherwise does not necessarily constitute or imply its endorsement, recommendation, or favoring by the United States Government or any agency thereof. The views and opinions of authors expressed herein do not necessarily state or reflect those of the United States Government or any agency thereof. 

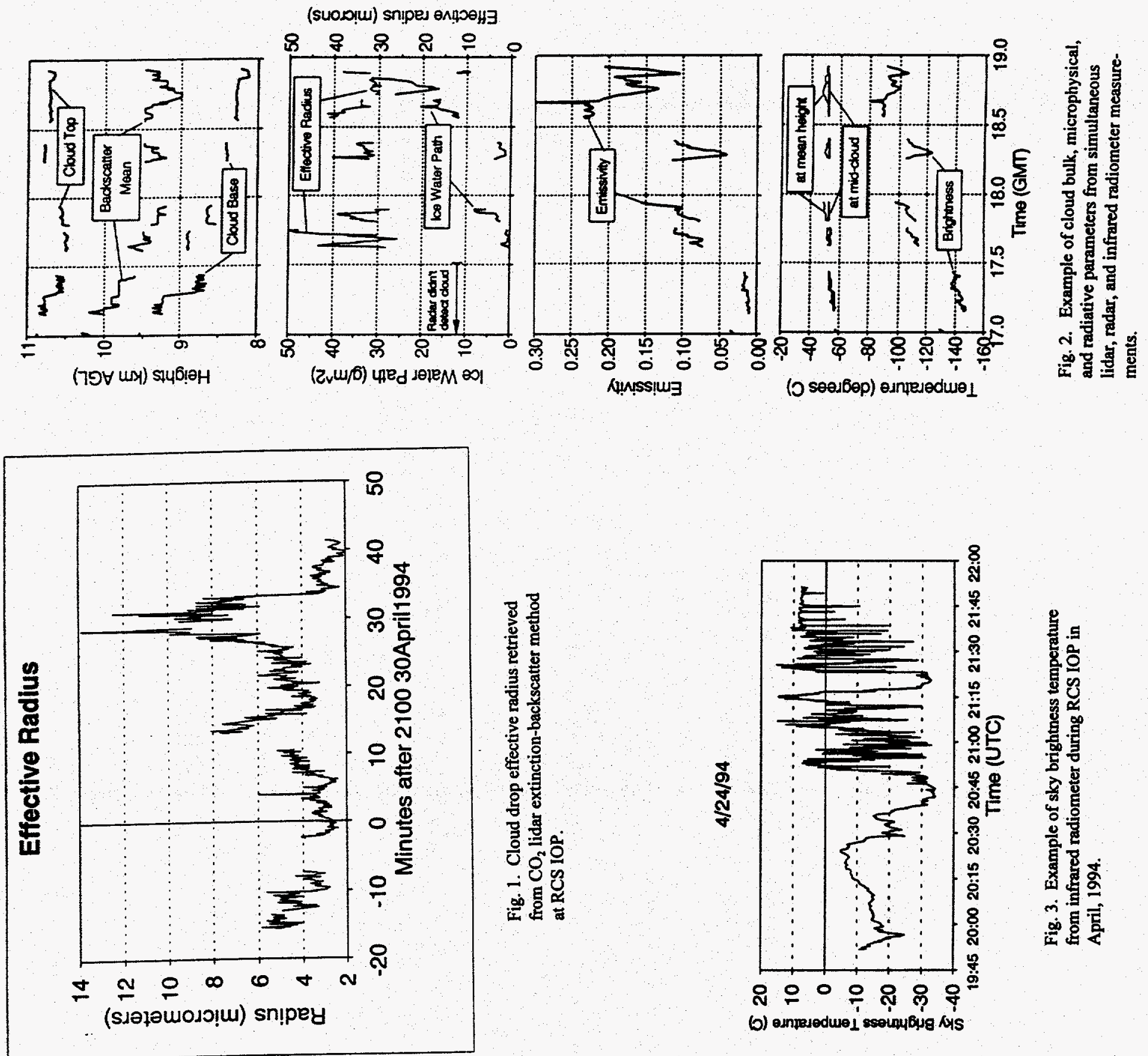

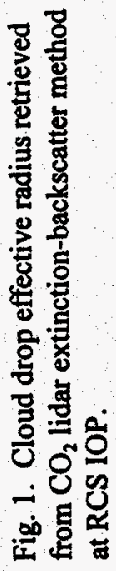

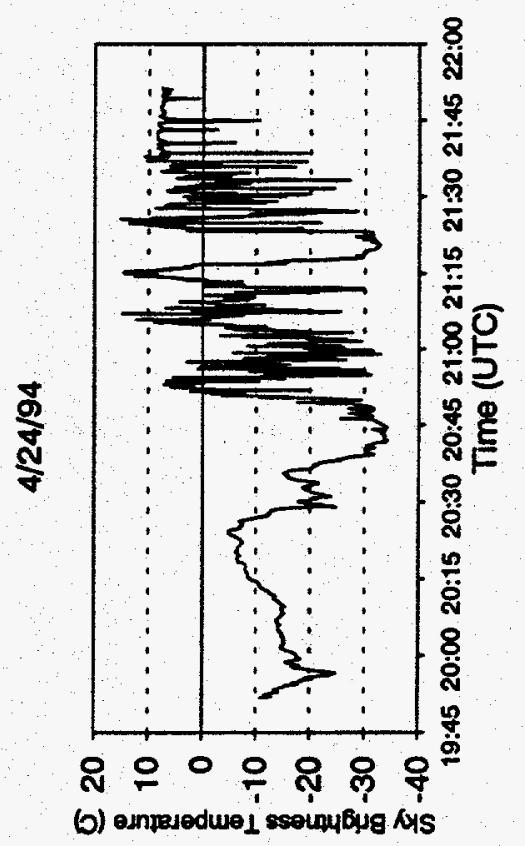

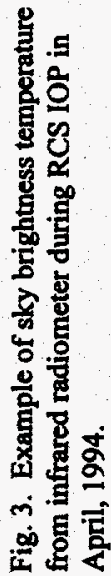




\section{DISCLAIMER}

This report was prepared as an account of work sponsored by an agency of the United States Government. Neither the United States. Government nor any agency thereof, nor any of their employees, makes any warranty, express or implied, or assumes any legal liability or responsibility for the accuracy, completeness, or usefulness of any information, apparatus, product, or process disclosed, or represents that its use would not infringe privately owned rights. Reference herein to any specific commercial product, process, or service by trade name, trademark, manufacturer, or otherwise does not necessarily constitute or imply its endorsement, recommendation, or favoring by the United States Government or any agency thereof. The views and opinions of authors expressed herein do not necessarily state or reflect those of the United States Government or any agency thereof. 